\title{
CAmplatio \\ O projeto de Sistema Nacional de Arquivos em Moçambique e o desafio na estruturação da área
}

\author{
Rafael Simone Nharreluga \\ Doutor; Universidade Eduardo Mondlane, Maputo, Moçambique; \\ rafalluga@yahoo.com.br
}

\begin{abstract}
Resumo: A concepção de sistema nacional de arquivos como uma entidade é recorrente no pensamento e nas práticas arquivísticas em Moçambique. O respectivo projeto, assim como o processo de sua implementação neste País, tendem a não se referir a essa noção como um mecanismo para a implementação de uma política nacional de arquivos, para entendê-la como uma política em si. Esse processo adquire matizes específicos, considerando a falta de estrutura de arquivos, em nível nacional, que compreenda serviços e instituições arquivísticos. Nessa direção, a pesquisa, de caráter qualitativa, adotou como recurso metodológico a contextualização histórica da noção de sistema nacional de arquivos e sua relação com a concepção de políticas arquivísticas, para posterior análise não apenas das três leis instituidoras de igual número de versões do projeto de Sistema Nacional de Arquivos em Moçambique, mas também das várias representações empíricas. Baseado na pesquisa bibliográfica e documental, e visando estimular um debate sobre a necessidade de uma estrutura organizacional de arquivos em Moçambique sustentada por políticas arquivísticas, o artigo aponta possíveis desafios, atores, estratégias e ações inerentes à eventual estruturação dessa área no País.
\end{abstract}

Palavras-Chave: Sistema Nacional de Arquivos. Políticas públicas de arquivos. Instituições arquivísticas. Serviços arquivísticos. Moçambique.

\section{Introdução}

O Sistema Nacional de Arquivos em Moçambique, reiterado e reificado, tem sido concebido pelos diversos grupos, instituições e atores arquivísticos moçambicanos como um projeto sustentável e estruturante que poderá conduzir ao conhecimento arquivístico e à ação necessária à organização dos arquivos como uma área profissional. Sob este entendimento, o conhecimento arquivístico e seus representantes tornam-se nulos, passando a prática arquivística a nortear-se por uma ordem identificada com o projeto de Sistema Nacional de Arquivos que, além de anular o conhecimento e os profissionais arquivísticos, tende a fundamentar-se nela mesma, examinando as fontes do saber arquivístico e o grau da sua justificação. Nesse sentido, a ordem atrelada ao referido projeto em Moçambique constitui uma doutrina do saber e da prática 
arquivísticos. E como tal, no decurso do projeto, a ordem adquiriu paulatinamente a posição mais universal da consciência dos atores arquivísticos, de tal forma que, entre estes, existe um consenso que dá conta de que os problemas dos arquivos em Moçambique não são estruturais, mas de natureza moral em relação à implementação do projeto de Sistema Nacional de Arquivos. Portanto, essa limitação atinge todo o tecido arquivístico nacional e seus representantes, independentemente da posição que cada um destes ocupa na área, condicionando a organização e gestão arquivísticas à realização do projeto de sistema.

Tendo em vista estimular o debate sobre a necessidade de estruturação da área dos arquivos em Moçambique enquanto um campo profissional, esta pesquisa procura mapear as iniciativas e tendências do projeto de Sistema Nacional de Arquivos neste País, analisando as sucessivas leis que o instituem nos diferentes momentos, de 1992 a 2018, tendo em conta o desafio na organização da área, em um país que não conta com instituições arquivísticas públicas nem serviços arquivísticos na estrutura do Estado. Sob este aspecto, Jardim, ao refletir sobre a política nacional de arquivos no Brasil, define a instituição arquivística como "o órgão responsável pela gestão, recolhimento, preservação e acesso dos documentos gerados pela administração pública, nos seus diferentes níveis de organização" (JARDIM, 2011, p. 4). E considerando as instituições arquivísticas públicas como uma categoria operacional em sua pesquisa, o mesmo autor define-as como sendo "aquelas organizações cuja atividade-fim é a gestão, recolhimento, preservação e acesso de documentos produzidos por uma dada esfera governamental” (JARDIM, 2011, p. 7), interpretando o Arquivo Nacional, os arquivos estaduais e os arquivos municipais, no caso brasileiro, como exemplos de instituições arquivísticas públicas. Entretanto, Jardim diferencia instituições arquivísticas de serviços arquivísticos, definindo estes como aqueles referentes "às unidades administrativas incumbidas de funções arquivísticas nos diversos órgãos da administração pública, no âmbito dos quais se configuram como atividades-meio" (JARDIM, 2011, p. 7).

Trata-se de observar, igualmente, como a noção de sistema nacional de arquivos tende a ser referida nos instrumentos legais instituintes do respectivo projeto e como o processo de sua implementação em Moçambique tem influenciado a construção do campo arquivístico nacional. 
Sustentada pelas realizações do Arquivo Histórico de Moçambique (AHM) dos anos $1980^{1}$, a origem do projeto de Sistema Nacional de Arquivos no território moçambicano suscitou, desde então, entre os seus proponentes e defensores, a concepção de uma política arquivística em si mesma, voltada tanto para a ampliação das ações arquivísticas até então desenvolvidas pelo AHM quanto para a sistematização de novas ações em nível nacional. Deste modo, entre os atores arquivísticos moçambicanos, é recorrente o pensamento que remete à solução dos problemas dos arquivos neste País, à implementação do projeto de Sistema Nacional de Arquivos iniciada em 1992 pelo Decreto 33/92 e, sucessivamente, continuada pelos decretos 36/2007 e 84/2018, respectivamente, em 2007 e 2018.

Decorridos 14 anos da primeira versão do sistema, em 2006 foram diagnosticados problemas estruturais relevantes que, posteriormente, não foram tomados em conta. Essa atitude sugere que, no estudo realizado, as falhas foram apreciadas como solucionáveis e mais tarde, na prática, teriam sido abandonadas supostamente por serem insolúveis ou irrelevantes. Observadas as limitações para a sua análise ou solução no quadro do projeto de sistema, contudo, tais problemas são relevantes e seu diagnóstico, no seio de outros de natureza estrutural, afigura-se fundamental perante o desafio da organização da área dos arquivos em Moçambique.

Buscou-se, portanto, visualizar o processo de implementação do projeto de Sistema Nacional de Arquivos em Moçambique à luz das iniciativas da Organização das Nações Unidas para a Educação, a Ciência e a Cultura (UNESCO) e seus determinantes que preconizam as políticas de informação como um pré-requisito à construção daquela noção.

Associamos, igualmente, nesta perspectiva, uma variante empírica identificada na Resolução 46/2006, de 26 de dezembro daquele ano, cujo conteúdo sintetiza um diagnóstico da realidade arquivística nacional feito pelo governo, após dificuldades na adoção da primeira versão do sistema. Essa Resolução, em seu conteúdo, constituiu-se em uma base para a institucionalização da segunda versão do sistema. Ao fazer menção a problemas estruturais, a mesma Resolução identifica elementos que denotam uma dimensão inerente à construção de uma política nacional de arquivos, aspecto fundamental que antecede a ideia de sistema nacional de arquivos. Com essa variante empírica, portanto, buscamos observar em que medida tais problemas foram 
equacionados nas duas versões do sistema que se seguiram ao lançamento daquela Resolução, situando o estado de redimensionamento do projeto, através da análise das várias representações legais e dos atores arquivísticos e suas ações no processo de implementação do projeto.

Elaborado com base na pesquisa bibliográfica e documental, com o objetivo de estimular um debate sobre a necessidade de medidas estruturantes na organização da área de arquivos em Moçambique, o artigo centra-se na análise das iniciativas e tendências do atual projeto de Sistema Nacional de Arquivos, apontando possíveis desafios, atores, estratégias e ações inerentes à eventual estruturação da área de arquivos no País.

\section{A relação entre a noção de sistema nacional de arquivos e a concepção de políticas arquivísticas}

Os projetos de sistemas nacionais de arquivos se inserem dentro da perspectiva das propostas de sistemas de informação que surgem na década de 1960, a partir de algumas empresas, nos Estados Unidos da América, envolvidas em estudos de casos sobre o planejamento (PRINCE, $1975^{2}$ apud NHARRELUGA, 1999, p. 26), bem como pela ação da UNESCO, na mesma década, "como promotora do debate internacional sobre a comunicação e a informação" (JARDIM, 1995, p. 19). A ação da UNESCO, nesse sentido, destaca-se na configuração do seu programa intergovernamental denominado Sistema Mundial de Informação Científica e Tecnológica (UNISIST) e no desdobramento deste no conceito de Sistemas Nacionais de Informação (NATIS) que, ao se sobressair como um dos resultados da Conferência Intergovernamental sobre o planejamento das infraestruturas nacionais de documentação, bibliotecas e arquivos organizada pela UNESCO em 1974, foi abandonado na década de 1980, apesar da pertinência dos seus objetivos, devido à insatisfação no processo de sua implantação na maior parte dos países (JARDIM, 1995). Ao observar essa insatisfação, a UNESCO, desde então, “desloca o conceito de NATIS para pontos periféricos dos seus discursos e amplia progressivamente um papel central das reflexões e ações de incentivo às políticas nacionais de informação" (JARDIM; SILVA; NHARRELUGA, 2009, p. 4). 
Ao destacar o crescente abandono do NATIS pela UNESCO, Jardim (1995) observa que a perspectiva de sistemas nacionais de informação manteve-se constante no discurso daquela Organização como estratégia de ordenação de recursos e infraestruturas nacionais de informação, porém, norteada pela formulação de políticas nacionais de informação como "pré-requisito a tal empreendimento em termos mais incisivos que no projeto de NATIS" (JARDIM, 1995, p. 28).

Observadas as matizes quanto à aplicação do primado das políticas de informação em projetos de sistemas de informação nos diversos países em desenvolvimento, os postulados da UNESCO, sobretudo quanto ao NATIS, influenciaram os debates e ações que resultaram na formulação e adoção de projetos de sistemas nacionais de arquivos em alguns países. Portanto, é nesse sentido que as iniciativas da UNESCO embasam os projetos de sistemas nacionais de arquivos em países em desenvolvimento e, em Moçambique, em particular, com implicações diretas no processo de implementação desses projetos.

Em Moçambique, do ponto de vista de concepção e execução do projeto de Sistema Nacional de Arquivos, em suas três versões, a formulação de políticas públicas arquivísticas não é uma precedência. Essa perspectiva contrapõe-se aos postulados atuais que, desde as iniciativas da UNESCO de delineamento de novos parâmetros pós NATIS, a partir da década de 1980, sugerem que o sucesso de qualquer programa de ação na área de informação está condicionado à formulação e implementação de políticas de informação (GUINCHAT; MICHEL, 1994; JARDIM, 1995).

Sem transpor esse cenário de configuração histórica dos projetos de sistemas nacionais de arquivos, Jardim (1995) reconhece as políticas de informação, nos termos da UNESCO, como pré-requisito à concepção de sistemas nacionais de informação, enfatizando a dimensão das políticas públicas arquivísticas, por ele definidas como

[...] o conjunto de premissas, decisões e ações - produzidas pelo Estado e inseridas nas agendas governamentais em nome do interesse social - que contemplam os diversos aspectos (administrativo, legal, científico, cultural, tecnológico, etc.) relativos à produção, uso e preservação da informação arquivística de natureza pública e privada (JARDIM, 2006, p. 10).

A partir de Jardim (2006), depreende-se que, além das ações no Estado, na Sociedade, nas relações Estado-Sociedade e Sociedade-Estado que identificam ações 


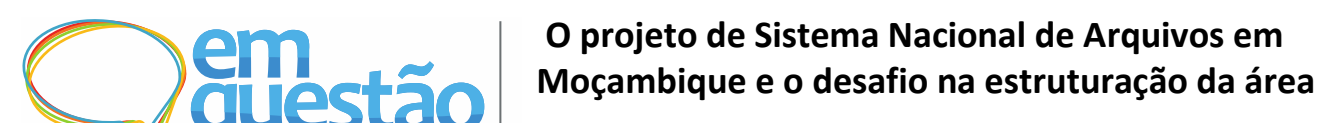

Rafael Simone Nharreluga

das políticas públicas arquivísticas, destacam-se o alto grau de transversalidade (relação com outras políticas públicas) dessas políticas e sua distinção com legislação arquivística que, segundo o autor, quando adequadamente concebida, além de fornecer elementos normalizadores à política arquivística, constitui instrumento e objeto das mesmas políticas.

Portanto, concebida a política arquivística nesses termos, o reconhecimento da sua importância é determinante para o sucesso da prática arquivística, podendo prevenir a reedição de erros ou situações já denunciadas e contribuir para o desenvolvimento da área, além de aliviar o Estado, de certa maneira, dos contornos inerentes ao financiamento de projetos arquivísticos não estruturantes. Esse seria o caso do projeto de Sistema Nacional de Arquivos em Moçambique que, mesmo abandonado em outros quadrantes do mundo e denunciado pelo seu principal percursor internacional, acaba por ser reiterado e reificado ao longo do tempo no território moçambicano. Entretanto,

\begin{abstract}
Considerando-se a abordagem sistêmica, entende-se que não cabe ao sistema implementar políticas arquivísticas. Sua função é favorecer a execução destas políticas pelos órgãos que o compõem mediante um processo de interação sistêmica. Um sistema como o proposto não é um órgão executor de políticas públicas (JARDIM, 2008, p. 11).
\end{abstract}

Com base neste autor, compreende-se que a política arquivística, ainda que possa ser influenciada pelo sistema arquivístico (quando ele efetivamente funciona), mas este prevalece como produto - e não causa - daquela, de tal forma que,

O sistema, neste caso, é um modelo de gerenciamento, entre outros que podem ser tomados como ferramenta na condução de políticas arquivísticas. [E que] Seja qual for a anatomia do sistema, da rede ou dos programas de ação, sua concepção e operacionalização decorrem da política arquivística (JARDIM, 2006, p. 11).

A partir do quadro acima traçado, entendemos o sistema nacional de arquivos como um mecanismo ou uma forma de operacionalização de uma política nacional de arquivos e a compreendemos, por isso mesmo, como um pré-requisito em relação àquele. Na mesma linha, sem atentarmos para o grau de sua realização ou não, concebemo-lo como um modelo de gestão de documentos e arquivos num contexto e 
âmbito marcado pela existência de uma estrutura constituída por entidades arquivísticas, consideradas no quadro de uma política da área.

\section{O Sistema Nacional de Arquivos na versão de 1992: o princípio da "grande ideia"}

O projeto de Sistema Nacional de Arquivos em Moçambique tem sua origem identificada pelo Decreto 33/92, de 26 de outubro daquele ano, que institui a primeira versão do sistema depois de um conjunto de ações realizadas pelo AHM na década de 1980, cujo reconhecimento pelo Estado teria legitimado esta instituição como proponente e coordenadora da mesma versão do sistema, concebendo-se, deste modo, como um arquivo nacional. É imprescindível lembrar que, entre as ações levadas a cabo pelo AHM nos anos 1980, o processo de recolhimento de documentos de arquivo que se destaca neste período viabilizou a construção da componente ideológica do Estado, que encontra fundamento na dimensão informacional e cultural representada nos arquivos coloniais recolhidos.

O Decreto em alusão relaciona, no seu preâmbulo, os arquivos ao processo de "tomada de decisões dos órgãos do Estado", bem como à promoção de "direitos dos cidadãos", um desiderato que, mesmo retomado no quadro legal do diagnóstico apresentado em 2006, não encontra realização no âmbito do projeto em curso.

Do ponto de vista da estrutura, integram o sistema, de acordo com o parágrafo segundo do artigo cinco, “o Arquivo Histórico de Moçambique, os arquivos centrais, os arquivos correntes nos diferentes órgãos do Estado, e outras entidades e os arquivos especiais existentes ou a serem criados". A considerar por esta estrutura, portanto, notase uma tendência para a formatação de um sistema de arquivos dos órgãos centrais ou, pelo menos, abrangendo apenas os órgãos situados ao nível da capital do País. Esta tendência é mantida pelo artigo nove que, ao referir-se à custódia pelo AHM, com caráter permanente, dos documentos recolhidos dos órgãos centrais, preconiza que a mesma pode ser descentralizada, designadamente, no âmbito regional e provincial e em função da natureza ou suporte da informação. Ora, salvo melhor entendimento, essa descentralização não é no quadro da estrutura do sistema, visto que os supostos 
domínios arquivísticos situados no âmbito regional e provincial, além de não serem mencionados na estrutura acima referida, nunca existiram.

Esta versão é relevante na medida em que sua estrutura compreende ou prevê domínios arquivísticos. Contudo, além da falta de harmonia entre os supostos arquivos indicados como parte da estrutura do sistema, os arquivos referidos como integrantes do sistema, excepto o AHM, não foram instituídos durante toda a vigência da mesma versão, de 1992 até sua extinção em 2007. A criação dos arquivos centrais foi facultativa nos termos do parágrafo quarto, do artigo 14, sendo a implantação do sistema prevista para ser "feita gradualmente, mediante plano de prioridades e de acordo com as disponibilidades orçamentais e financeiras do Estado" (Artigo 22). Decorridos 15 anos de implementação desta primeira versão do sistema, essa disponibilidade nunca se efetivou. É preciso ressaltar, ainda, que a existência de arquivos correntes a serem referidos como parte da estrutura do sistema decorreria da gestão de documentos e não de qualquer intenção que não inclua este procedimento técnico arquivístico.

Baseada em arquivos fictícios e, nesse imaginário, sem abranger todas as esferas da organização do Estado, a estrutura idealizada dos arquivos que iriam compor o sistema, porém, nunca foi criada. É indispensável considerar, igualmente, que o próprio AHM, supostamente representante da esfera central do governo e com existência legal, não foi suficientemente institucionalizado em sua estrutura e funcionamento para assumir as funções de coordenador do sistema, ficando desprovido de recursos em todos os níveis de sua atuação, para fazer face à gestão técnica arquivística do sistema e, bem assim, da autoridade exigida no âmbito das funções de coordenação do mesmo sistema.

Observados alguns destes sinais que caracterizam o projeto iniciado em 1992, não restam dúvidas de que a ideia de sistema nacional de arquivos em Moçambique já foi lançada e que a sua grandeza ou capacidade para incorporar todo o universo arquivístico nacional se define mediante a sua reedição nos termos legais, sendo uma "grande ideia" quanto mais edições o projeto merecer. 
Rafael Simone Nharreluga

\section{0 diagnóstico da situação dos arquivos entre a versão de sistema de 1992 e a de} 2007

Ciente dos resultados pouco animadores alcançados no processo de implementação da primeira versão do sistema, o governo moçambicano instituiu, através da Resolução 46/2006, de 26 de dezembro daquele ano, a Estratégia de Gestão de Documentos e Arquivos do Estado (EGDAE), com o fim de introduzir

[...] um modelo uniforme que permita uma melhor organização e funcionamento das unidades documentais e arquivísticas das instituições do Estado, [e não só,] mas também que garanta o rápido desenvolvimento desta área face aos desafios que hoje se impõem (EGDAE, 2006, p. 1).

Este enunciado de intenções, ofuscado pelo espectro de um modelo sistêmico imaginário, supostamente capaz de organizar e pôr em funcionamento "unidades", como se não bastasse, inexistentes, traduz claramente a busca por soluções para problemas identificados. Isso, portanto, consubstancia um diagnóstico usado para intermediar a primeira versão fracassada - e que deveria ser transformada - e a nova versão que passou a ser sugerida pelo discurso governamental, supostamente para corrigir anomalias do passado e consolidar o projeto de sistema nacional de arquivos na atualidade.

Essa postura de superação poderia trazer novos contornos se fosse integrada dentro dos limites e possibilidades de uma política arquivística que, segundo Jardim (2006), pressupõe, além do conhecimento político, uma compreensão gerencial e técnico-científico não só da Arquivística, mas também de outras áreas do saber, incluindo a percepção profunda da realidade que se pretende alterar. Uma ação nesse sentido poderia contribuir para o desenvolvimento da área, numa visão mais holística, ética e participativa do que nos moldes atuais de busca por um projeto fracassado e denunciado em sua concepção histórica.

O mais importante nesta pesquisa, em sua breve alusão à Resolução 46/2006, de 26 de dezembro, prende-se ao fato de que os constrangimentos descritos, como os que caracterizam o estado atual da área de arquivos em Moçambique, são relevantes do ponto de vista da necessidade de sua superação. E, ainda no nosso entender, portanto, a 
sua apresentação na forma de um diagnóstico sugere uma visão estruturante da área, viável, porém, apenas no quadro de uma política arquivística e não de um sistema.

Decorridos 14 anos do processo de implementação da primeira versão do sistema, o governo, movido, em princípio, pela necessidade de determinar efetivamente os reais constrangimentos que ditaram o fracasso da primeira versão, após uma análise baseada em seminários de auscultação, sobretudo a partir de $2003^{3}$, apresentou, em 2006, um diagnóstico da realidade dos arquivos moçambicanos consubstanciado na Resolução 46/2006 acima referida.

Antes de apresentar os elementos de diagnóstico da realidade arquivística nacional, a EGDAE, ao considerar "os mais variados problemas que [...] enfermam [...] a área [dos arquivos] ao nível da Administração Pública", define os documentos de arquivos - retomando e ampliando o desiderato formulado na primeira versão do sistema - como instrumentos "chave de apoio à administração, à cultura, ao desenvolvimento científico e como elementos de prova e informação", cuja responsabilidade de gestão e proteção especial recai sobre o governo (EGDAE, 2006, p. $1)$.

Se essa visão sobre os documentos de arquivos é relevante, contudo, nesta Estratégia o governo flutua entre a necessidade de considerar a especificidade dos arquivos e o interesse pela generalidade documental. Portanto, se, por um lado, esse aspecto reflete problemas de terminologia, de outro, identifica um novo ator institucional na área dos arquivos ${ }^{4}$ na qual, incumbido a propor matéria ligada à gestão e organização de arquivos, deixa traços de sua própria esfera de ação ou influência, confundindo domínios distintos. Trata-se de uma iniciativa que tem em vista substituir um ator - o AHM - que, ainda que seja inerentemente arquivístico, na visão do Estado, não teve desempenho na área e no período em avaliação. Aliás, é nesse quadro que a EGDAE (2006) situa a necessidade de filiação do País, no âmbito da cooperação internacional, ao Conselho Internacional de Arquivos (CIA), pois, até então, era feita apenas através do AHM. Fora desta questão, é fundamental reconhecer a pertinência da Estratégia, do ponto de vista dos problemas que apresenta para a área dos arquivos e, bem assim, a prevalência de seu domínio sobre a mesma área.

Entre as constatações apresentadas pela EGDAE e que conformam o estado atual dos arquivos, destacam-se: 
Rafael Simone Nharreluga

a) falta de enquadramento institucional dos arquivos enquanto setores de trabalho nas diversas instituições do Estado, o que resulta na indefinição de seus objectivos e falta de alocação de verbas para assegurar o seu apetrechamento e funcionamento;

b) falta de profissionais qualificados e com formação técnica específica na área, agravada pela subvalorização dos poucos existentes e pela inexistência de carreiras específicas no quadro do Sistema de Carreiras e Remunerações;

c) falta de meios materiais e financeiros e de espaço físico para uma modernização e eficiente organização de arquivos;

d) disponibilização da informação no quadro do acesso à informação arquivística tendenciosa e predominantemente coberta de algum secretismo, sendo mais dependente da vontade e iniciativa individual do funcionário do que de orientações institucionais;

e) legislação arquivística desajustada aos desafios que hoje se impõem na organização e funcionamento da área de arquivos, ao que se recomenda a necessidade urgente de revisão dos decretos 33/92 de 26 de Outubro e 30/2001 de 15 de Outubro, ambos do Conselho de Ministros (EGDAE, 2006, p. 2).

Depois de identificar os principais problemas - nos termos acima apresentados que caracterizam a situação atual da área de arquivos em Moçambique, a EGDAE definiu ações estratégicas com vista a garantir e orientar a busca de soluções para cada um desses constrangimentos. Portanto, é neste âmbito que foi instituída a segunda versão do sistema, através do Decreto 36/2007, de 27 de agosto - revogando a anterior versão instituída pelo Decreto 33/92, de 26 de outubro -, como uma ação chave voltada a ajustar a legislação arquivística aos desafios impostos aos arquivos.

Em que pese o fato das ações estratégicas previstas para solucionar as lacunas na/da legislação arquivística serem inoportunas para o funcionamento da área, é importante considerar que, mais do que buscar melhorar a legislação, a EGDAE suscitou a revisão do Decreto 33/92, dando lugar ao Decreto 36/2007.

Ora, em princípio, a concepção e o processo de implementação do Decreto 36/2007 seguem as linhas gerais e estratégicas da EGDAE, buscando corrigir as anomalias detetadas na concepção do Decreto 33/92 e no decorrer do seu processo de implementação. Trata-se de um processo que busca resgatar um projeto iniciado há mais de uma década. Nesse quadro, altera-se a designação de Sistema Nacional de Arquivos - como era chamado na versão de 1992 - para a de Sistema Nacional de Arquivos do Estado (SNAE) ${ }^{5}$, agora sob a direção de um órgão central do Estado e execução de um novo ator não arquivístico, mas estratégico e, talvez por isso mesmo, não expresso na própria lei do sistema. O novo ator responsável pela execução do sistema - o Centro 
Nacional de Documentação e Informação de Moçambique (CEDIMO) - emerge na EGDAE, depois que as suas competências foram definidas no respectivo Estatuto Orgânico, em 2003, confundindo-o com uma instituição arquivística.

\section{O SNAE na versão de 2007: a materialização da "grande ideia" e seus efeitos}

O preâmbulo do Decreto 36/2007, de 27 de agosto, observa que esta versão do sistema surge da "necessidade de adequar o Sistema Nacional de Arquivos [referência à primeira versão do sistema] ao preconizado na Estratégia para a Gestão de Documentos e Arquivos do Estado". Portanto, essa visão não só identifica a EGDAE como a base da nova versão do sistema de 2007, como também sugere a realização dessa nova versão do sistema no âmbito da Estratégia, sua base legal inspiradora. Isso é relevante em nossa pesquisa na medida em que pode revelar momentos de ruptura e continuidade.

Equacionados no âmbito da Estratégia em referência, os problemas da área, além de não terem sido considerados, não encontraram uma solução na nova versão do sistema, como supostamente era esperado por muitos adeptos dessa visão. Mais do que isso, não houve redimensionamento do projeto de Sistema Nacional de Arquivos em Moçambique a partir dos problemas anteriormente detectados e que implicaram a necessidade de adequar sua primeira versão. Assim, se os constrangimentos anteriores à segunda versão não eram fundamentais para dar uma nova dimensão ao projeto, logo, suscitam-se dúvidas sobre os reais motivos que estiveram por detrás da institucionalização da nova versão do projeto, reeditando-se os mesmos problemas.

Nesse âmbito, interessa observar em que medida a nova versão do sistema responde aos constrangimentos relacionados pela EGDAE - e não só - e para os quais foi instituída como antídoto no âmbito das suas ações estratégicas. Com este exercício, não pretendemos dar primazia à perspectiva de sistema como solução de problemas empíricos, mas cotejar as representações que prevalecem na realidade arquivística moçambicana com a concepção teórica que define o sistema nacional de arquivos como um modelo de gerenciamento, entre outros, de políticas arquivísticas, através dos órgãos que o compõem.

A partir destas considerações, parece relevante revisitamos os constrangimentos apresentados pela EGDAE, mapeando, tanto no cômputo geral da situação dos arquivos 
em Moçambique, apresentada por esta Estratégia, quanto no particular das determinações do Decreto 36/2007, o grau de solução daqueles no quadro das novas orientações e práticas. De forma resumida e em relação ao primeiro aspecto enquadramento institucional dos arquivos -, a institucionalização de unidades administrativas arquivísticas dentro das instituições públicas como forma de garantir a integração dos arquivos na estrutura das instituições do Estado não aconteceu. Em relação ao desenvolvimento de recursos humanos, com a exceção da ação inerente às carreiras específicas dos profissionais de arquivos que, além de pertinente, foi relativamente esboçada, as ações estratégicas desenhadas nesse âmbito não são apropriadas à solução do problema identificado. Sobre o reforço da capacidade institucional, a falta de enquadramento institucional dos arquivos comprometeu todos os esforços voltados à mobilização e alocação racional de recursos necessários para o apetrechamento e funcionamento de possíveis unidades administrativas arquivísticas nas diversas instituições do Estado, na medida em que estas não foram criadas, isto é, toda a provisão de infraestruturas, recursos materiais, financeiros e humanos que tenha sido levada a cabo não foi feita em prol dos arquivos, mas contra o desenvolvimento dos mesmos em sua representação como uma área de atividade profissional. A respeito do acesso à informação, a disponibilização da informação, devidamente identificada como "tendenciosa e predominantemente coberta de algum secretismo [e caracterizada como dependente] da vontade e iniciativa individual do funcionário do que de orientações institucionais" (EGDAE, 2006, p. 2) encontra, nas respectivas ações estratégicas, um tratamento que, diverso do tipo de problemas que enfermam o acesso à informação, está em consonância, porém, com as atuais orientações institucionais sob a égide do CEDIMO. Tais orientações põem em prática a "segurança da informação" junto das instituições produtoras de documentos, contra qualquer orientação profissional de acesso à informação arquivística que, consagrado pelos princípios de acesso aos arquivos adotados pela Assembleia Geral do Conselho Internacional de Arquivos em 2012, se efetiva através e junto de instituições arquivísticas.

Os problemas identificados e apresentados pela EGDAE são estruturais e, por isso mesmo, a sua resolução exige a concepção de políticas arquivísticas. Isso significa que cada um desses problemas excede as ações concretas e particulares que tenham sido planificadas estrategicamente para a sua solução. Nesse sentido, a EGDAE representa 
apenas a dimensão estrutural dos problemas que caracterizam a área dos arquivos em Moçambique, cuja solução tem sido sistematicamente adiada para sustentar a prevalência de um projeto não estruturante.

A partir dos elementos acima expostos, passamos a analisar a estrutura do decreto que institui a segunda versão do sistema. Na sua alínea $e$ ) do artigo primeiro (das Definições), essa versão do sistema introduz as figuras de "unidades de gestão documental" enquanto seções orgânicas previstas a funcionarem "junto dos órgãos centrais, provinciais e distritais do SNAE". Entretanto, se, por um lado, tais "unidades de gestão documental" nunca existiram como unidades orgânicas nas diversas instituições produtoras dos documentos, de outro, os chamados "órgãos centrais, provinciais e distritais do SNAE" não são unidades orgânicas arquivísticas. Pelo contrário, são órgãos presentes nos diferentes níveis de organização governamental para a consecução das funções primordiais do Estado e de cujo funcionamento resulta a produção de documentos arquivísticos. São esses documentos, portanto, que clamam por uma gestão arquivística a ser exercida por unidades administrativas de cunho arquivístico - serviços arquivísticos -, instituídas dentro de tais órgãos, onde funcionariam sob a orientação técnica de instituições arquivísticas em cada esfera governamental.

Ainda neste âmbito, o artigo cinco, depois de versar, no parágrafo primeiro, sobre a composição dos órgãos do sistema - apontados como sendo: $a$ ) órgão diretor central; b) órgãos centrais; c) provinciais; $d$ ) distritais - afirma, no parágrafo terceiro, que

[...] os órgãos centrais, provinciais e distritais referidos nas alíneas $b$ ), c) e $d$ ) do número um [...], compreendem, cada um e a seu nível [...], arquivos correntes; unidades de gestão de documentos dos arquivos intermediários; comissões de avaliação de documentos.

Entretanto, com a exceção dos órgãos referidos no parágrafo primeiro do artigo cinco, que existem legalmente instituídos, na estrutura do Estado, com atribuições diversas às da gestão arquivística, as unidades aludidas, retoricamente, no parágrafo terceiro, do mesmo artigo, como sendo partes integrantes daqueles órgãos referidos no parágrafo primeiro do artigo cinco, salvo as comissões de avaliação de documentos, 
nunca existiram na estrutura das instituições da administração pública moçambicana durante toda a vigência do Decreto 36/2007 que instituiu a segunda versão do sistema.

Ainda no que concerne à estrutura, o parágrafo primeiro do artigo nove afirma que "segundo a necessidade e onde haja condições, será criado o Arquivo Provincial." Portanto, essa colocação desafia qualquer entendimento arquivístico, suscitando dúvidas sobre o âmbito do sistema em causa, se é ou não de arquivos. Sendo de arquivos, entretanto, a perspectiva facultativa na criação de arquivos provinciais ${ }^{6}$, além de revelar ambiguidades na aplicação da noção de sistema, confirma, nos termos de Jardim (2006, p.11), que a concepção e operacionalização de um sistema decorrem da política arquivística. Nesses termos, fica claro que a concepção de arquivos públicos - que contempla a dimensão institucionalizada, no caso de um Estado unitário como Moçambique, do Arquivo Nacional, dos arquivos provinciais, dos arquivos distritais ou municipais - tem sua maior realização no âmbito de uma política arquivística, que antecede a concepção e operacionalização de qualquer modelo, seja ele sistémico ou não, voltado para o seu gerenciamento. Outro aspecto relevante a considerar são os chamados "outros órgãos do sistema" - o Conselho Nacional de Arquivos (CNA) e a Comissão Nacional de Avaliação de Documentos (CNAD) - que, de acordo com o artigo 17, "são instituídos, junto do órgão director central", um ministério, ou seja, um dos órgãos centrais do Estado.

Entendida nesses termos, a versão de sistema de 2007 não compreende serviços e instituições arquivísticos na sua constituição. Inexistentes na estrutura das instituições da administração pública, as unidades arquivísticas que deveriam integrá-las como parte orgânica e, por essa via, compor o sistema através dos respectivos subsistemas, são confundidas com as instituições cujos documentos deviam gerir. Isto é, as instituições da administração pública nos diversos níveis da estrutura do Estado compõem, elas mesmas - não através de seus representantes orgânicos instituídos para a gestão arquivística -, a estrutura do sistema. O mesmo acontece com a única instituição arquivística existente no País. Não fazendo parte diretamente da estrutura do sistema, ela é referida, no parágrafo quarto do artigo cinco, como "o órgão de gestão de documentos na fase permanente e de assessoria ao órgão director central do Sistema", tendo como funções específicas, "participar na elaboração de normas técnicas de gestão 
de documentos; participar na harmonização e monitoria dos processos de avaliação de documentos dos arquivos intermediários" (Artigo 8).

Portanto, fica evidenciada a "grande ideia" no âmbito do projeto de Sistema Nacional de Arquivos em Moçambique, cujo efeito é a incorporação de todo o universo arquivístico nacional, moldando a consciência e as práticas dos atores arquivísticos.

\section{O SNAE na versão de 2018: equívocos no objeto reiterado}

O projeto de Sistema Nacional de Arquivos, reiterado ao longo do tempo, persiste nesta terceira versão desprovido de entidades arquivísticas em sua composição, numa perspectiva em que, se a prática arquivística nacional não é pautada por uma política nacional de arquivos, tampouco as leis que instituíram as sucessivas versões daquele projeto de sistema apontam parâmetros de uma possível política nacional de arquivos.

O Decreto 84/2018, de 26 de dezembro, que institui a terceira versão do sistema anuncia, no parágrafo primeiro do artigo dois, das disposições gerais, figuras de “Arquivos dos Órgãos Centrais; Arquivos dos órgãos da Província; Arquivos dos Órgãos do Distrito; Arquivos dos Órgãos das Autarquias Locais”, denominando-as de "subsistemas do SNAE". Essa perspectiva parece retomar e, de certa forma, ampliar a suposta estrutura de arquivos idealizada no âmbito da primeira versão e que, sem nunca ter sido implementada, foi abandonada na segunda versão do sistema. Considerando, porém, a ênfase que é dada a esses arquivos fictícios, logo no início do decreto, enquanto "subsistemas do SNAE", a composição do SNAE suscita dúvidas, pois a concepção de subsistemas de arquivos enquanto representantes diretos das instituições da administração pública seria melhor deduzida na estrutura do sistema onde figurar-seiam como partes de um todo, representados por instituições arquivísticas instituídas em cada esfera do governo. Portanto, sua ênfase seria no âmbito da regulamentação do funcionamento do sistema para situar os serviços arquivísticos que representam neste e para esboçar a sua relação com as respectivas instituições arquivísticas nos diferentes níveis governamentais, tomando estas enquanto integrantes diretos do sistema.

O artigo seis da estrutura do sistema enumera quatro entidades - "Órgão Diretor Central; Órgão Coordenador; Órgão de Assessoria e Gestão de Documentos na Fase Permanente; Órgão de Gestão de Informação Classificada" - ao lado dos diferentes 
órgãos da esfera político-administrativa do Estado (Órgãos Centrais; Órgãos da Província; Órgãos do Distrito; Autarquias Locais), designando-os, em conjunto, como “Órgãos de Gestão do SNAE”. Sobre estes órgãos, portanto, sobressai a sua posição como componentes da estrutura do sistema e a sua função como órgãos de gestão. É curioso que, com a exceção do AHM, supostamente designado como "Órgão de Assessoria e Gestão de Documentos na Fase Permanente", os demais não são arquivos, nem representantes arquivísticos dos órgãos governamentais nos diversos níveis da organização político-administrativa do Estado. Ao que se pode observar, as primeiras quatro entidades fazem parte da assim chamada estrutura do sistema por conveniência das atribuições que receberam. Mas os outros órgãos referidos nos quatro níveis de organização governamental, sendo eles produtores de documentos de arquivo no desempenho de suas respectivas funções, estariam dimensionados no sistema não como integrantes diretos, mas através dos respectivos subsistemas, denominados nesta versão como "subsistemas do SNAE". O chamado Sistema Nacional de Arquivos do Estado compreenderia instituições arquivísticas representando, cada uma e em seu respectivo nível, a organização político-administrativa do Estado - central, provincial, distrital ou municipal -, tendo os arquivos dos órgãos situados nos respectivos níveis de organização do Estado como seus subsistemas. As instituições arquivísticas, nesses termos, se existissem, essas sim seriam os órgãos de gestão técnica de um sistema nacional de arquivos, resolvendo-se a gestão administrativa dos subsistemas no âmbito dos respectivos órgãos de tutela.

O parágrafo primeiro do artigo oito da "Gestão de Arquivos" afirma que

[...] os órgãos referidos no artigo anterior [Órgão Director Central; Órgão Coordenador; Órgão de Assessoria e Gestão de Documentos na Fase Permanente; Órgão de Gestão de Informação Classificada; Órgãos Centrais; Órgãos da Província; Órgãos do Distrito; Autarquias Locais], cada um ao seu nível, dispõem de arquivos correntes e intermediários [e, especificando ainda mais, destaca que os últimos três, bem como o] Órgão de Assessoria e Gestão de Documentos na Fase Permanente [...], incluem o arquivo permanente.

Fica evidente que os arquivos que formam os "subsistemas do SNAE" correspondem apenas a conjuntos documentais - ora designados de arquivos correntes, intermediários e permanentes -, desprovidos de uma definição, tanto como resultado de um processo de organização, de acordo com o uso que se faz dos mesmos, quanto como 
setores orgânicos instituídos junto dos diversos órgãos do Estado. Enfatizados no âmbito da lei, contudo, tais subsistemas do SNAE são fictícios do ponto de vista de iniciativa da estrutura de arquivos.

Portanto, ficam evidenciados os equívocos em torno do projeto de Sistema Nacional de Arquivos em Moçambique, cuja reedição em três versões corrobora a ideia de um objeto imaginário.

\section{Contornos de um objeto imaginário e reiterado: a estruturação da área em questão}

O projeto de Sistema Nacional de Arquivos em Moçambique, em suas três versões, não é estruturante para a organização da área dos arquivos neste País, sendo desprovido de uma estrutura constituída por entidades arquivísticas. Isso sugere que, desde os primórdios desse projeto moçambicano portanto, pretendeu-se organizar ou modificar uma realidade desconhecida, em um contexto em que também não se dispõe de conhecimento para modificar tal realidade. Falta entendimento para orientar politicamente essa área de atividade profissional, assim como uma política do conhecimento, cuja implementação viabilizaria o exercício técnico-profissional em nível nacional.

A busca por um Sistema Nacional de Arquivos em Moçambique, nos últimos 29 anos, tem sido observada fora da concepção de uma estrutura de arquivos que reflita a organização do Estado, na qual deduzir-se-ia o funcionamento dos mesmos através de sua concepção atrelada ao funcionamento das diversas instituições governamentais nos diferentes níveis da organização do Estado como setores legalmente instituídos e organizados, capazes de intervir tecnicamente sobre os conjuntos de documentos nas respectivas instituições e níveis do governo, sob a assistência de um Arquivo Nacional legalmente constituído. Isso significaria conceber os arquivos como uma área de atividade profissional distinta e autônoma. E, nesse contexto, os arquivos seriam entendidos enquanto setores de trabalho, em referência tanto a unidades administrativas incumbidas de realizar serviços de arquivo dentro das respectivas instituições produtoras dos conjuntos documentais (serviços arquivísticos) quanto de entidades 
administrativas incumbidas da gestão arquivística nas diferentes esferas da estrutura político-administrativa do Estado (instituições arquivísticas).

A falta dessa compreensão na realidade arquivística moçambicana dificulta a conformação dos arquivos - enquanto uma área de atuação profissional - em duas redes referenciadas mutuamente, de um lado, a de serviços técnico-arquivísticos dentro de cada instituição da administração pública e, de outro, a de instituições arquivísticas em cada esfera do governo - central, provincial, distrital ou municipal. As duas redes funcionariam sob um modelo centralizado ou descentralizado que identifica o papel de intervenção do Arquivo Nacional em um grau maior ou menor, respectivamente.

Falta uma rede de arquivos públicos em Moçambique da qual, além da atual concepção de patrimônio documental arquivístico nacional, tanto em seu acervo acumulado quanto em relação aos documentos ainda em processo de produção, deveria emergir um modelo de instituição arquivística pública. Nesse sentido, implica a reflexão, por um lado, em torno de recursos humanos e materiais, legislação e tratamento técnico para determinar as modificações necessárias e urgentes àquela concepção de património e, de outro, da estrutura organizacional adequada ao funcionamento de uma instituição arquivística na consecução de seus objetivos específicos ${ }^{7}$.

Se, por um lado, a reedição de incongruências no âmbito do processo de busca por um Sistema Nacional de Arquivos em Moçambique exige conhecimento e dinâmica institucionais para produzir mudanças, de outro, o fracasso que caracteriza esse processo em suas três versões desde 1992 confirma a gênese dos projetos de sistemas nacionais de arquivos - enquanto uma das dimensões dos sistemas nacionais de informação - em países em desenvolvimento junto de organizações como a UNESCO, onde nascem fracassados e denunciados em função do processo de sua implementação exigir políticas públicas de informação como pré-requisito.

Fora do contexto histórico em que se destaca o seu fracasso, num país como Moçambique, onde faltam infraestruturas de informação e que não conta com nenhuma política de informação, é quase impossível ainda supor sucesso na adoção de um sistema nacional de arquivos que não contempla atores arquivísticos profissionais. Fracassados e denunciados nos organismos internacionais em que foram idealizados, os projetos de sistemas nacionais de arquivos foram mantidos em alguns países em 
desenvolvimento como mecanismos para a gestão de documentos e arquivos - como atesta um estudo ${ }^{8}$ do Programa de Gestão de Documentos e Arquivos (RAMP, sigla em inglês) da divisão do Programa Geral de Informação (PGI) da UNESCO, elaborado no âmbito de um contrato desta com o Conselho Internacional de Arquivos (CIA) -, depois que os países desenvolvidos - com destaque para EUA e Canadá -, longe da concepção de sistemas nacionais de arquivos, estabeleceram programas de gestão de documentos e arquivos em seus respectivos países (INDOLFO, 2013) ${ }^{9}$.

Nesse âmbito, se o que se pretende em Moçambique é a gestão de documentos e arquivos, então se torna urgente abandonar o projeto de Sistema Nacional de Arquivos nesse país para se tomar medidas condizentes à gestão de documentos e arquivos, em uma iniciativa de construção do campo arquivístico nacional, norteado pela formulação e implementação de políticas públicas arquivísticas em termos mais incisivos que no projeto atual.

Em todos os momentos de construção do projeto de Sistema Nacional de Arquivos em Moçambique, o AHM, criado no período colonial como Arquivo do governo da colônia, prevaleceu - e ainda prevalece - como único domínio arquivístico em nível nacional, contra a inexistência, tanto de outras instituições arquivísticas, com as quais formaria uma rede de instituições arquivísticas públicas ${ }^{10}$ distribuídas, cada uma em seu nível de organização do Estado, quanto de serviços arquivísticos nas diferentes instituições públicas, onde funcionariam como unidades administrativas incumbidas de serviços técnicos arquivísticos, no âmbito dos quais se configurariam como atividades-meio. A concepção destes dois segmentos e seu funcionamento integrado constitui um aspecto de uma política pública arquivística e não de sistema.

Proponente da primeira versão do sistema, da qual se tornou coordenador, em reconhecimento de seu empenho arquivístico do período que antecedeu esta versão, atuando em condições estruturais muito precárias, o AHM não prevaleceu nas duas versões seguintes como coordenador, nas quais, mesmo sendo única instituição arquivística em nível nacional, inclusive, mereceu atribuições marginais. Assim, se a primeira versão do projeto de sistema não se constituiu em uma iniciativa estruturante, pelo menos representou uma tendência que marcou a sobrevivência da única instituição arquivística na realidade nacional com um certo prestígio. Essa imagem imprecisa e indeterminada que o AHM representou durante a primeira versão do sistema, no 
entanto, ficou ainda mais comprometida nas duas versões seguintes do projeto de sistema, tornando-se numa simples instituição, cada vez mais periférica e sem protagonismo no cenário arquivístico nacional.

Ao invés do AHM, observado o fracasso na implementação da primeira versão do sistema, o CEDIMO passou a liderar a realização do diagnóstico da realidade dos arquivos em nível nacional no período que antecedeu a institucionalização da segunda versão do sistema, despontando desta forma, na segunda versão, como coordenador. Sem ser enunciado no âmbito do decreto que instituiu essa versão, a instituição estratégica do governo na área dos arquivos a partir dos anos de 2000 sempre operou nessa área valendo-se, porém, na sua atuação, não somente das atribuições definidas no quadro do seu Estatuto Orgânico de 2003 - no qual o seu papel em relação ao sistema foi claramente definido -, que a integram na área de arquivos, como também de sua subordinação administrativa ao "órgão director central do SNAE".

Independentemente do sentido estruturante ou não que essa medida possa representar, ela deduz uma iniciativa que pode ser entendida no âmbito da necessidade de impor uma nova "dinâmica" na área, operando a substituição de atores e suas posições no campo de ação. Nesse âmbito, se não se pode falar em iniciativas de redimensionamento do projeto de Sistema Nacional de Arquivos em Moçambique, pelo menos se observa uma tendência de reposicionamento estratégico de atores no campo arquivístico, revelando a manutenção de um projeto político, não estruturante na organização e funcionamento dos arquivos.

Em que pese a nova dinâmica que vem sendo empreendida pelo CEDIMO na área dos arquivos em Moçambique nos últimos anos, que deriva da legitimidade político-administrativa e legal que assiste essa instituição em sua operação, dotando-a de condições estruturais favoráveis, ela não é dotada, porém, de um mínimo de conhecimento técnico-científico e de experiência arquivísticas - se comparado ao AHM - para a assunção das funções que tem desempenhado na área.

Em nosso entender, toda a dinâmica necessária para uma área profissional se compadece com o profissionalismo e os ditames técnicos-científicos dessa mesma área. Assim sendo, se a dinâmica que se pretende na área dos arquivos não é movida por outros interesses fora da necessidade de colocá-los ao serviço, primeiro, do processo de tomada de decisões dos respectivos órgãos produtores e, em consequência, à promoção 
de direitos de cidadania, de cultura e do desenvolvimento científico, é motivo para ponderar na alocação e disposição de vários atores no campo não só de arquivos como em qualquer outro de atuação profissional.

Sob esse aspecto, enquanto única instituição arquivística em nível nacional, a refundação do AHM em todas as suas dimensões é urgente para adequá-la à atual exigência de organização e gestão arquivísticas em nível nacional. Caso essa visão não seja oportuna, seria o caso de transformar o CEDIMO - sem descurar da experiência do AHM -, de uma instituição com funções mistas para uma instituição arquivística e reorientar as suas competências, dotando-o de capacidade técnico-científica para além de suas atuais competências político-administrativas. Se nenhuma dessas opções se mostrar viável, abre-se espaço para a criação de uma instituição arquivística pública de âmbito nacional - independente das duas instituições -, aglutinando o que há de melhor nas duas, na definição das suas atribuições. Entretanto, qualquer que seja a opção, ela deve ocorrer dentro da perspectiva de uma política nacional de arquivos, diferentemente dos termos atuais de busca por um projeto que não contribui para a organização e desenvolvimento da área.

Nesse âmbito, é imprescindível, igualmente, promover a criação de serviços arquivísticos nas instituições públicas, além de instituições arquivísticas em cada esfera governamental, ante o avanço implacável da reiteração e reificação do projeto de Sistema Nacional de Arquivos no País. Nesse sentido, as ações arquivísticas passariam a se exprimir junto dessas entidades concretas e específicas que, ao desenvolver suas funções arquivísticas, nas instituições públicas produtoras dos documentos de arquivos, observando as diversas esferas de exercício do poder estatal, estarão a promover iniciativas que favorecem o desenvolvimento arquivístico do País. A criação dessas entidades requer, por conseguinte, a definição de atribuições e prioridades específicas, bem como a alocação de recursos em todos os níveis, tendo em conta a necessidade de formulação e execução de programas nacionais ou setoriais de arquivos por parte dessas entidades e não por outras situadas fora do domínio arquivístico.

Enfim, é preciso considerar que, além do desafio premente e inadiável na organização da área de arquivos em Moçambique, a essência arquivística no contexto global e as transformações operadas pelas tecnologias de informação e comunicação têm mostrado uma mobilidade extraordinária em sua dinâmica científica, colocando 
novos desafios à área. As soluções para todos esses desafios devem ser encontradas na área dos arquivos sob a liderança dos respectivos profissionais em colaboração com diversos profissionais de outras áreas de conhecimento.

\section{Considerações finais}

As leis analisadas neste artigo não escondem a carência de sistematização conceitual e de alinhamento arquivístico. Sem atentarmos para a relação causa-efeito, bem como questões de caráter técnico-científico inerentes à gestão e organização arquivísticas, supor que um modelo marcadamente imaginário possa organizar e pôr em funcionamento domínios existentes igualmente na imaginação constitui, no mínimo, um contra-senso.

A ideia de que o Sistema Nacional de Arquivos em Moçambique é uma entidade dotada de conhecimento - e que, por isso mesmo, dispensa a necessidade de existência de entidades arquivísticas estruturadas - e cujo único valor do conhecimento arquivístico é aquele revelado sob o signo do governo, subverte a área dos arquivos em Moçambique e todo o desígnio inerente à sua organização. Uma área de atividade profissional, ainda que o seu objeto seja produto da atividade governamental, se for sustentável porque a única fonte do conhecimento técnico-científico é o próprio governo (que inclusive é quem determina o seu valor), na verdade, é uma área insustentável profissionalmente porque se transforma em uma atividade política. Não se pretende, com isso, sugerir uma despolitização da área dos arquivos. Porém, seria relevante se o envolvimento político na área fosse acompanhado por uma posição clara, contra o atual disfarce baseado em instituições e seus profissionais engajados cujo resultado são os disparates que caracterizam a área.

Faltam alternativas na organização dos arquivos em Moçambique porque não há política. A área dos arquivos que deveria ser ativa e relevante profissionalmente para criar as competências exigidas no âmbito da gestão estatal e não só, como também do exercício da cidadania, garantindo ao cidadão acesso aos documentos, na comprovação dos seus direitos e deveres frente ao Estado ou na investigação científica, fica refém à falta de alternativas estruturantes. Nesse contexto, a prática arquivística em Moçambique vem sendo exercida como uma atividade política. As instituições que 
atuam na área e seus profissionais engajados tentam, a todo o custo, produzir na mente de todo o mundo, todos os dias, a visão de que a falta de alternativas na organização e desenvolvimento da área não constitui nenhum problema, quando, na verdade, o que ocorre é que a prática arquivística não é exercida como uma atividade profissional que compreenda, entre seus resultados, a produção de conhecimento arquivístico independente e crítico. Assim, com implicações diretas na organização e gestão arquivísticas, o campo arquivístico nacional, em suas diversas dimensões, vem sendo construído em torno e sob a influência do projeto de Sistema Nacional de Arquivos, reiterado ao longo de 29 anos e reificado pelos seus proponentes e admiradores.

Presente na imaginação de seus proponentes e defensores, o projeto de Sistema Nacional de Arquivos em Moçambique constitui um instrumento discursivo para sustentar o domínio governamental sobre a área dos arquivos contra qualquer orientação profissional. A soberania sobre a área, que tem aquele projeto como sua base, atua de forma integrada entre os grupos, as instituições e os atores que exercem influência no campo, em uma visão que envolve os benefícios de uma política ativa, fragmentando, desse modo, uma possível resistência dos profissionais que, no caso moçambicano, não têm a produção de conhecimento arquivístico como sua bandeira. Independentemente das qualificações exigidas para o efeito - bastante escassas na área dos arquivos no contexto nacional -, é preciso lembrar que a produção de conhecimento científico é muitas vezes vista como um campo de articulação da resistência que torna, por isso, seus autores apartados dos benefícios de uma política ativa e, assim, alvos de todo o tipo de interpretações e ataques.

Como se pode depreender a partir dos diferentes dispositivos legais analisados, a gravidade e complexidade dos problemas arquivísticos moçambicanos revelam que quanto mais se buscam soluções, mais se padece de bases teóricas e metodológicas para se lidar com eles. Muitas foram as novidades introduzidas na área dos arquivos em Moçambique nos últimos anos, mas elas não foram capazes de operar mudanças profundas no cenário arquivístico nacional. Relevantes do ponto de vista de sua iniciativa, contudo, apenas criaram outras perspectivas e uma nova agenda cujo aprofundamento teórico - baseado em pesquisas - poderá contribuir para a elevação da Arquivística no cenário nacional para além de um simples corpo de condutas e de receitas sem racionalidade científica e possibilitar a superação das práticas existentes. 
Com a escassez de produção de conhecimento científico na área em nível nacional, as instituições e seus profissionais desempenham um papel importante e influenciam sobremaneira as práticas e, por isso, devem, no âmbito de sua atuação de cariz pragmática, se distanciar do empirismo e buscar uma fundamentação teórica no tratamento e organização dos arquivos.

Enfim, a área dos arquivos em Moçambique precisa operar uma ruptura para se posicionar como um domínio de conhecimento científico, fazendo uma autocrítica profunda, em uma visão de abertura para o diálogo com outras áreas do saber - não no sentido de levar a Arquivística para fora, mas de trazer o conhecimento não arquivístico para dentro, a fim de organizar o setor -, sem descurar da aliança com o seu aliado natural, o Estado, enquanto maior produtor de arquivos de todos os tempos.

\section{Referências}

GUINCHAT, C.; MICHEL, M. Introdução geral às ciências e técnicas da informação e documentação. Brasília: IBICT, 1994.

ICA (International Council on Archives). Principles of access to archives adopted by the Annual General Meeting, 2012. Disponível em:

$<$ https://www.ica.org/sites/default/files/ICA_Access-principles_EN.pdf> Acesso em: 23 mar. 2020.

INDOLFO, A. C. Dimensões político-arquivísticas da avaliação de documentos na Administração Pública Federal (2004-2012). 2013. Tese (Doutorado em Ciência da Informação) - Curso de Pós-Graduação em Ciência da Informação, Universidade Federal do Rio de Janeiro, Rio de Janeiro, 2013.

JARDIM, J. M. Em torno de uma política nacional de arquivos: os arquivos estaduais brasileiros na ordem democrática (1988-2011). In: REUNIÃO BRASILEIRA DE ENSINO E PESQUISA EM ARQUIVOLOGIA, 2., 2011, Rio de Janeiro. Anais [...]. Disponível em:

https://sites.google.com/a/arquivistica.org/reparq/reparq2011/trabalhos/aprovados. Acesso em: 15 dez. 2015.

JARDIM, J. M. Políticas públicas arquivísticas: princípios, atores e processos. Arquivo \& Administração, Rio de Janeiro, v. 5, n. 2, p. 5-16, jul./dez. 2006.

JARDIM, J. M. Políticas públicas de informação: a (não) construção da política nacional de arquivos públicos e privados (1994-2006). In: ENCONTRO NACIONAL DE PESQUISA EM CIENCIA DA INFORMAÇÃO, 9., São Paulo, 2008. Anais [...]. Disponível em: http://www.ancib.org.br/pages/anais-do-enancib.php. Acesso em: 10 fev. 2020. 
Rafael Simone Nharreluga

JARDIM, J. M. Sistemas e políticas públicas de arquivos no Brasil. Niterói: EDUFF, 1995.

JARDIM, J. M.; SILVA, S. C. A.; NHARRELUGA, R. S. Análise de políticas públicas: uma abordagem em direção às políticas públicas de informação. Perspectivas em Ciência da Informação, Belo Horizonte, v.14, n.1, p.2-22, jan./abr. 2009.

MOÇAMBIQUE. Decreto n. 33/92, de 26 de outubro de 1992. Institui o Sistema Nacional de Arquivos. Boletim da República. Maputo, n. 43, p. 1-3, 26 out. 1992. Série I.

MOÇAMBIQUE. Decreto n. 36/2007, de 27 de agosto. Altera o Sistema Nacional de Arquivos criado pelo Decreto n. 33/92, de 26 de Outubro, passando a denominar-se Sistema Nacional de Arquivos do Estado (SNAE). Boletim da República. Maputo, $\mathrm{n}$. 34, p. 22-106, 27 ago. 2007. Série I.

MOÇAMBIQUE. Decreto n. 84/2018, de 26 de dezembro. Aprova a revisão do Sistema Nacional de Arquivos do Estado (SNAE) e revoga o Decreto n. 36/2007, de 27 de agosto. Boletim da República. Maputo, n. 252, p. 2-35, 26 dez. 2018. Série I.

MOÇAMBIQUE. Resolução n. 2/2003. Aprova o Estatuto Orgânico do Centro de Documentação e Informação de Moçambique (CEDIMO). Boletim da República. Maputo, n. 30, p. 336-337, 23 jul. 2003. Série I.

MOÇAMBIQUE. Resolução n. 46/2006, 26 de dezembro. Aprova a Estratégia para a Gestão de Documentos e Arquivos do Estado (EGDAE). Boletim da República. Maputo, n. 51, p. 122-127, 26 dez. 2006. Série I.

NHARRELUGA, R. S. A política e o sistema nacional de arquivos: o caso moçambicano. 1999. Monografia (Graduação em Arquivologia) - Curso de Graduação em Arquivologia, Universidade Federal Fluminense (UFF), Rio de Janeiro, 1999.

\title{
The National Archives System project in Mozambique and the challenge in structuring the area.
}

\begin{abstract}
The conception of the national archives system as an entity is recurrent in archival thinking and practices in Mozambique. The respective project as well as the process of its implementation in this country tend not to refer to this notion as a mechanism for the implementation of a national archives policy, to understand it as a policy in itself. This process takes on specific nuances considering the lack of archival structure, at national level, that includes archival services and institutions. In this sense, the research, of qualitative character, adopted as a methodological resource the historical contextualization of the notion of national archives system and its relationship with the conception of archival policies, for further analysis not only of the three
\end{abstract}




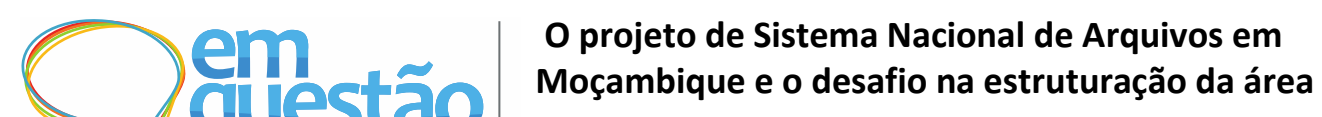

Rafael Simone Nharreluga

instituting laws of equal number of versions of the National Archives System project in Mozambique, but also from the various empirical representations. Based on bibliographic and documentary research, and aiming to stimulate a debate on the need for an organizational structure of archives in Mozambique, supported by archival policies, the article points out possible challenges, actors, strategies and actions inherent to the eventual structuring of this area in the country.

Keywords: National archives system. Archival public policies. Archival institutions. Archival services. Mozambique.

Recebido: 07/05/2020

Aceito: 07/08/2020

\section{Declaração de autoria}

Concepção e elaboração do estudo: Rafael Simone Nharreluga

Coleta de dados: Rafael Simone Nharreluga

Análise e discussão de dados: Rafael Simone Nharreluga

Redação e revisão do manuscrito: Rafael Simone Nharreluga

\section{Como citar}

NHARRELUGA, Rafael Simone. O projeto de Sistema Nacional de Arquivos em Moçambique e o desafio na estruturação da área. Em Questão, Porto Alegre, v.27, n. 1, p. 132-159, 2021. Doi: http://dx.doi.org/10.19132/1808-5245271.132-159

\footnotetext{
${ }^{1}$ Entre as realizações de maior impacto no percurso do AHM, sobretudo no período pós-colonial, destacase o processo de recolhimento dos anos 1980, cujo êxito suscitou a ideia de Sistema Nacional de Arquivos que viria a nascer em Moçambique na década de 1990. Relevante enquanto um processo arquivístico de impacto para a sociedade moçambicana e, considerando as condições em que foi realizado, entretanto, não se tratou de um processo decorrente de uma política pública de arquivos. Tratou-se, isso sim, de uma política de Estado voltada para a viabilização de sua componente ideológica que encontra fundamento na dimensão informacional e cultural representada nos arquivos coloniais recolhidos.

2 PRINCE, Thomas R. Sistemas de informação: planejamento, gerência e controle. Rio de Janeiro: Livros Técnicos e Científicos, 1975. Apud Nharreluga (1999).

${ }^{3}$ Entre os seminários, destaca-se o Seminário sobre a Estratégia de Implementação do Sistema Nacional de Gestão de Documentos, Registo e Arquivo na Administração Pública, realizado pelo CEDIMO em Maputo, entre os dias 14 e 16 de Abril de 2004.

${ }^{4}$ Para mais detalhes, consultar a Resolução 2/2003, de 2 de Junho, que aprova o Estatuto Orgânico do CEDIMO, atribuindo a esta instituição, competências (artigo três) que, mais do que ligadas à área de arquivos, são próprias de um Arquivo Nacional. Observe que, até então, o termo "Nacional" não era parte da designação desta instituição.
} 
${ }^{5}$ A designação da nova versão do sistema não é menos ambígua do ponto de vista jurídico, tendo em conta a dimensão de produção dos arquivos públicos não somente por instituições do Estado e as de caráter público, mas também por aquelas instituições de direito privado encarregadas de executar serviços de domínio público. Deste modo, essa designação sugere uma interpretação restrita que tende, desde a institucionalização dessa segunda versão do sistema, a impor o sigilo sem precedentes na gestão arquivística nacional sob a alegação de "segurança da informação" como apanágio na gestão estatal, comprometendo o uso social dos arquivos públicos que compreende tanto o uso comum pelos membros da coletividade sem discriminação entre os usuários e nem necessidade de consentimento estatal para este fim quanto o uso especial em que, por medidas de segurança na gestão do Estado e da vida privada, o indivíduo se sujeita a regras específicas e consentimento estatal.

${ }^{6}$ Num entendimento arquivístico aprovado, considerando a estrutura do Estado - central, provincial, distrital ou municipal -, nenhum sistema nacional de arquivos existiria sem os arquivos provinciais ou seus representantes.

${ }^{7}$ Para mais detalhes sobre estrutura organizacional e os objetivos específicos de uma instituição arquivística, consultar JARDIM, J. M. Instituições arquivísticas: estrutura e organização. A situação dos arquivos estaduais. Revista do Serviço do Patrimônio Histórico e Artístico Nacional, Rio de Janeiro, v. 21, p. 39-42, 1986.

${ }^{8}$ Consultar RHOADS, J. B. La función de la gestión de documentos y archivos en los sistemas nacionales de información: un estudio del RAMP. Paris: UNESCO, 1983.

${ }^{9}$ Em sua tese de doutorado, Indolfo (2013) disserta sobre o conceito de gestão de documentos e analisa estratégias e práticas adotadas por países como EUA e Canadá e que estimularam a aplicação desse conceito nos diferentes órgãos públicos daqueles países, respectivamente.

${ }^{10} \mathrm{Na}$ década de 2000, a ação que culminou com a integração do CEDIMO na área dos arquivos traduziu, fora dos ditames de uma política pública arquivística, uma política governamental que não incluiu a transformação e a adaptação dessa instituição com vista a dotá-la de capacidade técnico-científica para, em coordenação com o AHM, exercer funções e alcançar objetivos específicos identificados com os anseios inerentes à organização e desenvolvimento da área no País, considerando todo o legado arquivístico até então conquistado. Na década de 1990, os arquivos centrais, cuja criação foi prevista pelo decreto que instituiu a primeira versão do sistema, nunca foram criados. 